\title{
Influencing Factors and Evaluation Indexes of the Stress of Bridge Pile Foundation in Karst Area
}

\author{
Jian Xing ${ }^{1, a}$, Xichang $\mathrm{Xu}^{2, \mathrm{~b}}$ and Lingfa Jiang ${ }^{2, \mathrm{c}}$ \\ ${ }^{1}$ Highway Administration of Huizhou Municipality, Huizhou, 516008, China \\ ${ }^{2}$ Institute of Rock and Soil Mechanics, the Chinese Academy of Sciences, Wuhan ,430071,China \\ aemail: 32926493@qq.com, bemail: xcxu@whrsm.ac.cn, cemail: Ifjiang@whrsm.ac.cn
}

Keywords: Karst; Influencing Factors; Pile Foundation; Axial force

\begin{abstract}
It is a very complex problem of pile foundation stability evaluation in karst area, which has been gotten more and more attention in the engineering field. There are many factors that affect the mechanical properties of the pile foundation, including the size, quantity and spacing of the karst. In this paper, numerical simulation is carried out, the results show with the cave number increases, pile axial force increases overall. The larger the size of the cave or the smaller the spacing of the cave, the greater the additional axial force of the pile under the same depth. The cave size has the greatest influence on the additional axial force of pile, and the cave spacing has minimum influence.
\end{abstract}

\section{Introduction}

It is a very complex problem of pile foundation stability evaluation in karst area, which has been gotten more and more attention in the engineering field[1,2,3,4]. In the bridge pile foundation construction, due to the stiffness difference, when the pile through the beaded caves, it will make the filler inside the cave produce stress release effect, the soft filler is bound to consolidation settlement to resist the work produced the stress release, until the energy environment in the cave in a new equilibrium state. There are many factors that affect the mechanical properties of the pile foundation, including the size, quantity and spacing of the karst. Analysis of these factors on the mechanical properties of pile foundation has great significance to the design and construction of the bridge foundation[5,6]. Therefore, in this paper, base on the project Shuixi Bridge, according to these factors, numerical simulation is carried out, comparing and analyzing the effect of each factor to the mechanical properties of pile foundation, in order to obtain some beneficial conclusions from the computational results, and provide a reference for the design and construction of pile foundation in beaded karst region.

\section{Beaded karst geological model}

According to the advanced drilling, the formation from the new to the old of the Shuixi bridge are Quaternary artificial filled soil layer $\left(Q^{\mathrm{ml}}\right)$, Quaternary alluvial soil layer $\left(\mathrm{Q}^{\mathrm{al}}\right)$ and Quaternary residual soil layer $\left(\mathrm{Q}^{\mathrm{el}}\right)$, the underlying bedrock is mainly Carboniferous Bedrock $(\mathrm{C})$.

The beaded karst founded in the Shuixi Bridge, mostly contains 2 caves, and with a maximum of 4 caves. According to the advanced drilling and electromagnetic wave CT detection results, the beaded karst can be summarized into two types: 2 cave beaded model, 3 cave beaded model (see Figure 1).

\section{Comprehensive analysis of the effect of the beaded karst on the stress of the pile foundation}

The soil around the pile settlement is greater than pile settlement, the pile-soil relative displacement (or the relative displacement trends) is the main reason causing the friction, due to the consolidation settlement of the filler in the caves, the soil provides friction downward to the pile, resulting in negative side friction. The negative side friction of pile is not only unable to contribute 
to load the upper load, but also produces the drag load to the pile. It causes yielding or failure of pile foundation, pile damage, and uneven settlement of structure. Therefore, considering the effect of negative friction on pile foundation is one of the essential problems in the design of pile foundation.

The axial force of pile is increased by the negative side friction of pile, side friction of pile can be reflected by calculating the axial force of pile.

Additional axial force of pile influenced by the number of the karst cave is shown in Figure 2.
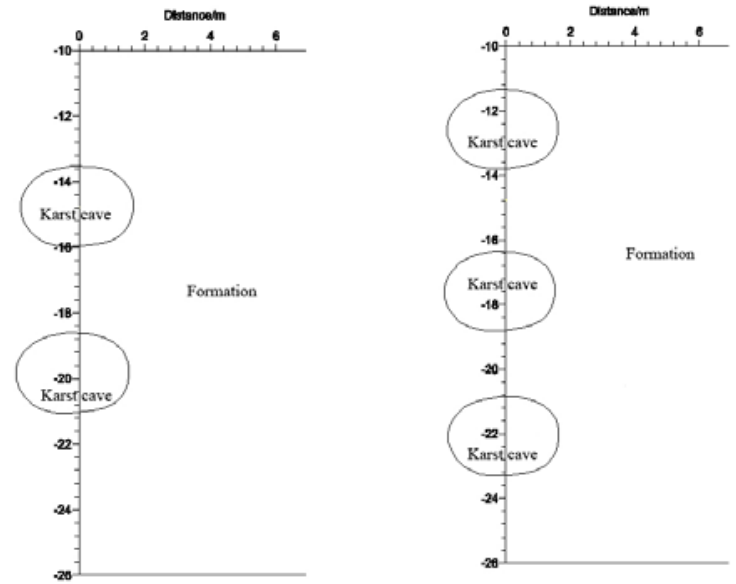

Fig.1. Conceptual model of the beaded karst

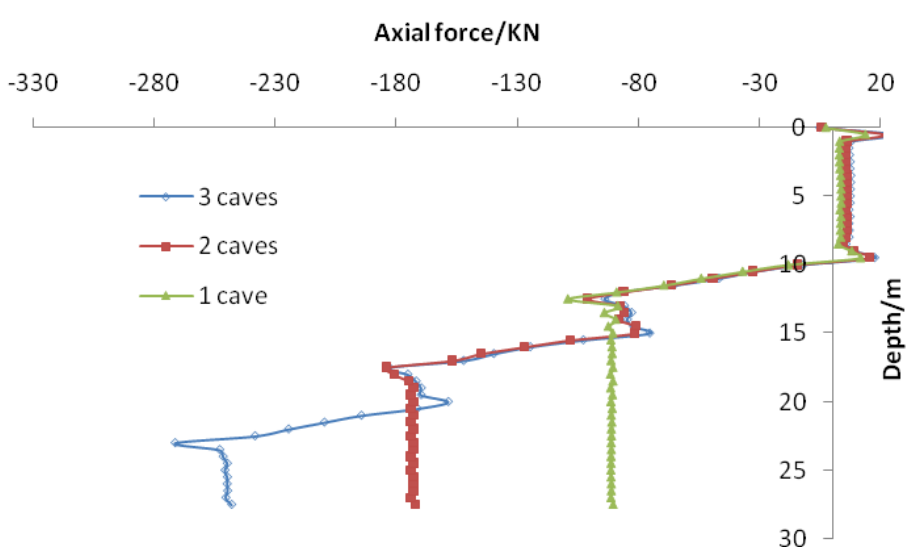

Fig.2. The additional axial force of pile influenced by the cave quantity

Under the different number of cave, from the pile top to the cave top, the pile has basically no additional axial force. When reached the cave area, the pile additional axial force increases rapidly, and it decreases after passing through the cave. Then, down to another area of the karst cave, the additional axial force of pile still increases rapidly, and then decreases. Until below the bottom of the karst area, the axial force of the pile remains unchanged. With the cave number increases, pile axial force increases overall, comparing 2 caves and 1 cave, and 3 caves and 2 caves, above the new cave area, pile additional axial force is similar, but within and below the new cave area, pile additional axial force increases significantly. At the bottom of the pile, the additional axial force of pile with 1, 2 and 3 caves are respectively 95, 173 and 248kN.

The additional axial force of pile influenced by the size of the karst cave is shown in Figure 3.

When the cave width is different, after the consolidation settlement of cave, pile additional axial force increases with the depth, from the pile top to the cave top, the pile additional axial force increases in little, in the cave range, the pile additional axial force increases rapidly, when increasing to a certain extent, below the bottom of the cave, the pile additional axial force remains almost unchanged. And the larger the size of the cave, the greater the additional axial force of the pile under the same depth. At the bottom of the pile, the additional axial force of pile with 2.4, 3.6 and $4.8 \mathrm{~m}$ cave width are respectively 157, 222 and $272 \mathrm{kN}$. 

4.

The additional axial force of pile influenced by the spacing of the karst cave is shown in Figure

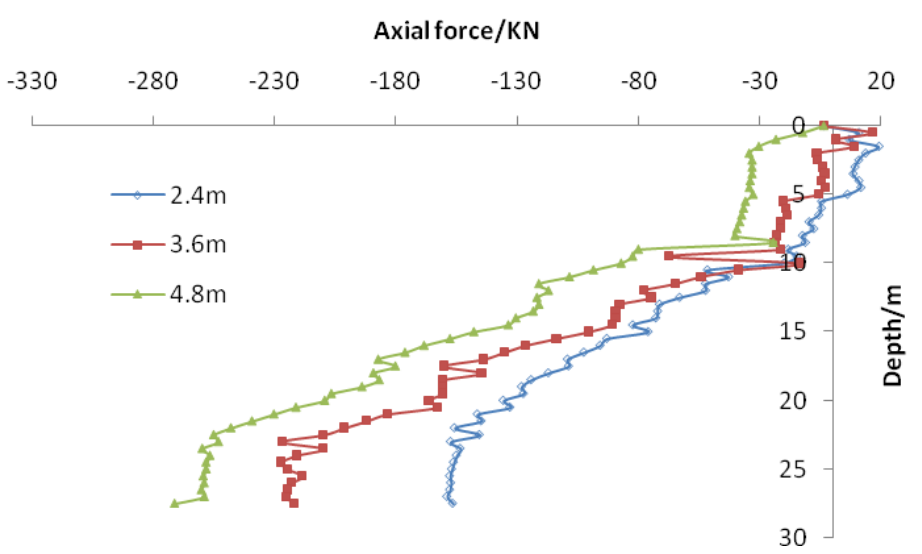

Fig.3. The additional axial force of pile influenced by the cave width

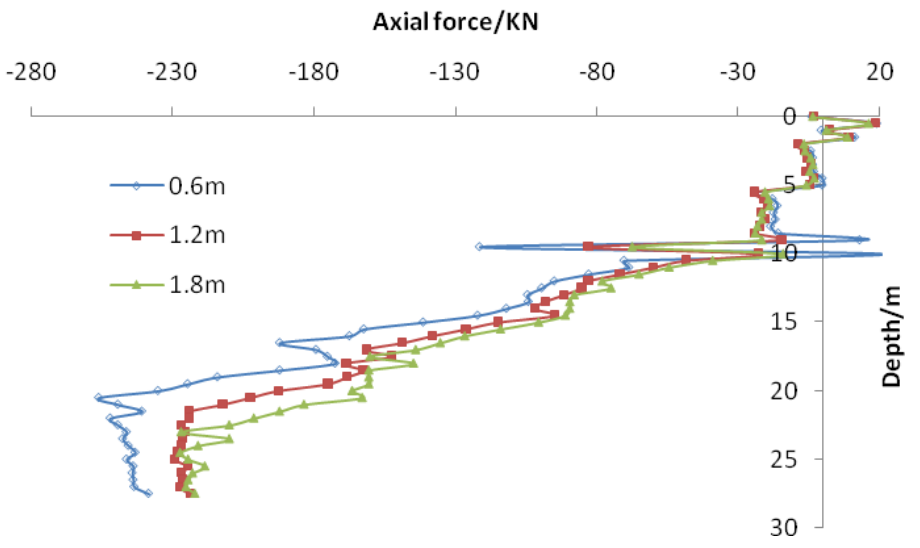

Fig.4. The additional axial force of pile influenced by the cave spacing

When the cave spacing is different, after the consolidation settlement of cave, pile additional axial force increases with the depth, from the pile top to the cave top, the pile additional axial force increases in little, in the cave range, the pile additional axial force increases rapidly, when increasing to a certain extent, below the bottom of the cave, the pile additional axial force remains almost unchanged. And the smaller the spacing of the cave, the greater the additional axial force of the pile under the same depth. At the bottom of the pile, the additional axial force of pile with 0.6, 1.2 and $1.8 \mathrm{~m}$ cave spacing are respectively 122,109 and $101 \mathrm{kN}$.

Figure 5 shows the variation law of the additional axial force of the pile foundation controlled by the consolidation settlement of the karst cave under different karst conditions.

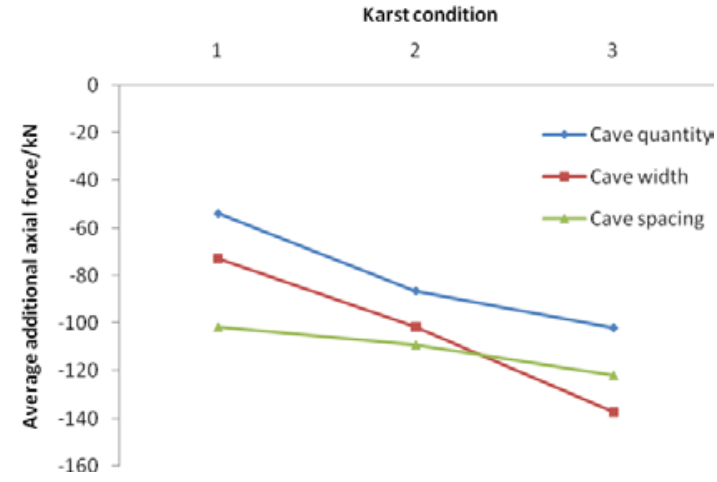

(a) Karst condition

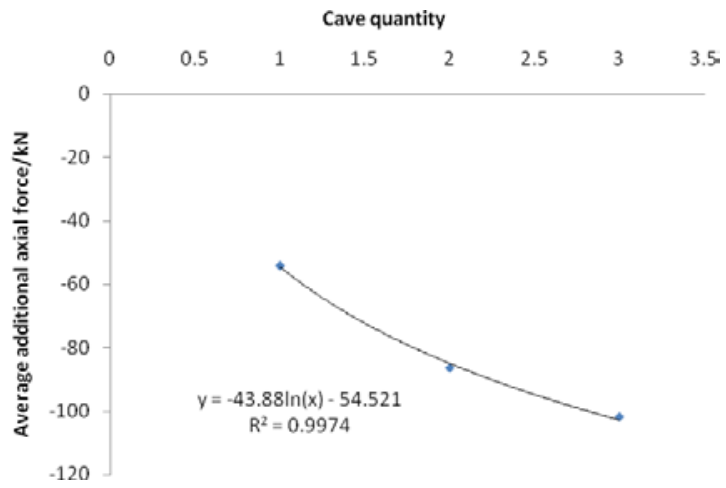

(b) Cave quantity 


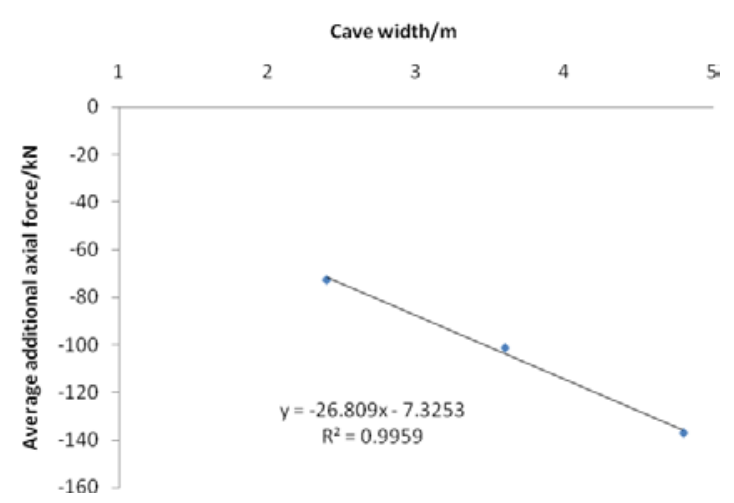

(c) Cave size

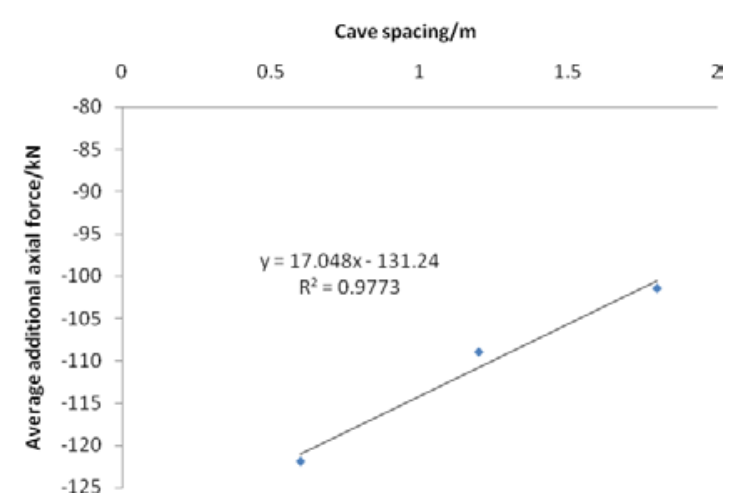

(d) Cave spacing

Fig.5. The additional axial force of pile under the influence of karst cave

(Karst condition 1,2,3 respectively represents the cave number 1,2,3; the cave width 2.4,3.6,4.8m; the cave spacing $1.8,1.2,0.6 \mathrm{~m}$ )

It can be seen from Figure 5(a), with the increase of the number of karst cave, the size of the cave and the decrease of the distance between the karst cave, the additional axial force of pile caused by the impact of the karst cave is gradually increasing.

The cave size has the greatest influence on the additional axial force of pile, under the same conditions of 3 caves, the cave width increases from $2.4 \mathrm{~m}$ to $4.8 \mathrm{~m}$, the additional axial force of pile increases from $73 \mathrm{kN}$ to $137 \mathrm{kN}$, in the case of a $100 \%$ increase in the size of karst cave, the additional axial force of pile increases $87.7 \%$.

The cave quantity has great influence on the additional axial force of pile, which increases from $54 \mathrm{kN}$ of one cave to $102 \mathrm{kN}$ of three caves, in the case of a $200 \%$ increase in the number of karst cave, the additional axial force of pile increases $88.9 \%$.

The cave spacing has minimum influence on the additional axial force of pile, under the same conditions of 3 caves, the cave spacing reduces from $1.8 \mathrm{~m}$ to $0.6 \mathrm{~m}$, the additional axial force of pile increases from $101 \mathrm{kN}$ to $122 \mathrm{kN}$, karst spacing decreases by $66.7 \%$, the additional axial force of pile only increases $20.8 \%$.

It can be seen from Figure 5 (b), with the increase of the number of karst cave, the additional axial force of pile increases, but the growth rate gradually decreases. Use the logarithmic function to fit the empirical formula, the correlation coefficient reaches 0.999 , the fitting formula is

$Q_{n}=43.88 \ln m+54.521$

where, $\mathrm{m}$ is the cave quantity.

It can be seen from Figure 5 (c), with the increase of the width of karst cave, the additional axial force of pile increases, use the linear function to fit the empirical formula, the correlation coefficient reaches 0.998 , the fitting formula is

$$
Q_{n}=26.809 b+7.3253
$$

where, $b$ is the cave width (m).

It can be seen from Figure 5 (d), with the decrease of the spacing of karst cave, the additional axial force of pile increases, use the linear function to fit the empirical formula, the correlation coefficient reaches 0.989 , the fitting formula is

$Q_{n}=-17.048 d+131.24$

where, $\mathrm{d}$ is the cave spacing $(\mathrm{m})$.

\section{Effect evaluation of the beaded cave on the stress of the pile foundation}

Using the proportion of pile average additional axial force of upper load to evaluate the effect of karst on bridge pile foundation, the control indexes can be seen in Table 1. 
Table 1 The pile average additional axial force evaluation index

\begin{tabular}{|c|c|c|c|}
\hline $\begin{array}{c}\text { Additional axial force /Upper load } \\
\text { (\%) }\end{array}$ & Cave quantity & $\begin{array}{l}\text { Cave width } \\
\text { (m) }\end{array}$ & $\begin{array}{l}\text { Cave spacing } \\
(\mathrm{m})\end{array}$ \\
\hline $1 \sim 4$ & 1 & $<2$ & $>4.2$ \\
\hline $4 \sim 5$ & $1 \sim 3$ & $2 \sim 2.5$ & $3.3 \sim 4.2$ \\
\hline $5 \sim 6$ & $3 \sim 6$ & $2.5 \sim 3.1$ & $2.4 \sim 3.3$ \\
\hline $6 \sim 7$ & $>6$ & $3.1 \sim 3.6$ & $1.5 \sim 2.4$ \\
\hline $7 \sim 8$ & \multirow{3}{*}{ / } & $3.6 \sim 4.5$ & $0.5 \sim 1.5$ \\
\hline $8 \sim 10$ & & $4.5 \sim 5.5$ & \multirow[b]{2}{*}{1} \\
\hline 10 15 & & 5.5 9.0 & \\
\hline
\end{tabular}

\section{Conclusion}

After the consolidation settlement of cave, pile additional axial force increases with the depth, from the pile top to the cave top, the pile additional axial force increases in little, in the cave range, the pile additional axial force increases rapidly, when increasing to a certain extent, below the bottom of the cave, the pile additional axial force remains almost unchanged. With the cave number increases, pile axial force increases overall. The larger the size of the cave or the smaller the spacing of the cave, the greater the additional axial force of the pile under the same depth. The cave size has the greatest influence on the additional axial force of pile, and the cave spacing has minimum influence.

\section{Acknowledgement}

This work was financially supported by the Guangdong traffic science and technology project (201407).

\section{Reference}

[1] Zheng, W. G., Xie, Y. C. Xue, X. B. Selection of pile foundations in karst areas. Chinese Journal of Geotechnical Engineering. 33(2011), 404-407.

[2] Zhou, B., Ni, W., Wang, H., \& Liu, Z. Research on bearing capacity of post-grouting pile groups as bridge foundations in karst areas, in: International Conference on Electric Technology and Civil Engineering. IEEE, 2011 pp.6115-6120.

[3] Lodigina, N., \& Sharapov, R. Calculation of pile foundations at the karst areas, in: International Conference on Mechanical Engineering, Automation and Control Systems. IEEE, 2014

[4] Jiang, C., Liu, L., Wu, J. P.. A new method determining safe thickness of karst cave roof under pile tip. Journal of Central South University,21(3), 2014, 1190-1196.

[5] Hua, S., Engineering, D. O.. Numerical simulation research on the stability of transmission tower pile foundations in a karst area of guangdong province. Carsologica Sinica, 33(1),2014, 44-50.

[6] Sun, Y., Zhang, Z., \& Zhang, H. . Analysis on parameter sensitivity of pile foundations stability in karst areas based on the theory of grey relation. Chinese Journal of Underground Space \& Engineering, 9(2),2013, 297-303. 